\title{
Lexis
}

Journal in English Lexicology

HS 1 | 2009

Lexicology \& Phonology

\section{A morphophonological approach to clipping in English}

Can the study of clipping be formalized?

Denis Jamet

\section{OpenEdition}

Journals

Electronic version

URL: http://journals.openedition.org/lexis/884

DOI: $10.4000 /$ lexis. 884

ISSN: 1951-6215

\section{Publisher}

Université Jean Moulin - Lyon 3

Electronic reference

Denis Jamet, " A morphophonological approach to clipping in English », Lexis [Online], HS 1 | 2009,

Online since 17 September 2009, connection on 30 April 2019. URL : http://journals.openedition.org/ lexis/884 ; DOl : 10.4000/lexis.884

\section{(c) (i) (9) $\Theta$}

Lexis is licensed under a Creative Commons Attribution-NonCommercial-NoDerivatives 4.0 International License. 


\title{
A morphophonological approach to clipping in English Can the study of clipping be formalized? ${ }^{1}$
}

Denis Jamet ${ }^{2}$

\begin{abstract}
In this paper, I will endeavor to define clipping, and see if there are any semantic differences between the multiplicity of terms: "shortening", "clipping", "truncations", etc. I will examine the semantic role of clipping, and try to answer the following question: is clipping a wordformation device? I will mainly focus on the consequences and phonological realizations of clipping in English to show that the phonological regularities in the formation of clipping make it a potential word-formation device, by shedding new light on the tendencies formalizing the study of clipping.
\end{abstract}

Key-words: clipping - truncation - clipping - phonology - lexicology - morphophonological realizations - linguistics

$* * *$

\section{Résumé}

Dans cet article, je reviens tout d'abord sur la définition de ce que l'on appelle troncation en français, mais shortening, clipping, truncation en anglais, afin de voir s'il y a des différences sémantiques entre les divers termes. J'examinerai le rôle sémantique de la troncation, puis tenterai de répondre à la question suivante : la troncation est-elle un procédé de création lexicale? Principalement, je me pencherai sur les conséquences et les réalisations phonologiques de la troncation, en mettant au jour les tendances qui permettent de formaliser l'étude de la troncation, afin de montrer que les régularités phonologiques des formes tronquées font de la troncation un parfait candidat pour être un procédé de création lexicale.

Mots-clés : troncation - phonologie - lexicologie - réalisations morphophonologiques linguistique

\footnotetext{
${ }^{1}$ Many thanks to Lucile Bordet and Manuel Jobert for the "phonological" help, and to Natalie Mandon-Hunter for proofreading the paper.

${ }^{2}$ Université Jean Moulin - Lyon 3. Centre d'Etudes Linguistiques - EA1663: denis.jamet@univ-lyon3.fr
} 


\section{Introduction}

In this paper, I would like to study one of the word-formation processes known as "shortening", "clipping" or "truncation", adopting a morphophonological approach. The present paper will be divided as follows: in the first part entitled "theoretical background: what is clipping?" I will endeavor to define clipping, and see if there are any semantic differences between the multiplicity of terms: "shortening", "clipping", "truncations", etc. The second part will examine the semantic role of clipping, and in the third part I will try to answer the following question: is clipping a word-formation device? The fourth and final part will focus on the consequences and phonological realizations of clipping in English to show that the phonological regularities in the formation of clipping make it a potential wordformation device.

In other words, the key-questions addressed in this paper are to decide whether or not the study of clipping can be formalized, i.e. given word-formation generative rules; whether clipping is part of morphology or phonology; and finally whether phonological constraints are more important than morphological constraints in order to formalize the study of clipping.

\section{Theoretical background: what is clipping?}

Quite paradoxically, clipping has more than one name. Depending on the reference books consulted, the same phenomenon is often referred to as "shortening", "clipping" or "truncation". The first task I would like to carry out is to see whether the three terms are really synonymous, or if they do not refer to different linguistic realities. Clipping and truncation seem to be quasi synonymous terms, clipping being the Anglo-Saxon term, whereas truncation is borrowed from French. The semantic difference lies in the use of the term "shortening", which seems to act as a hyperonym for clipping and truncation, but also for blends, backformations, acronyms, etc. I will further show that there are good reasons to differentiate these various word-formation devices, as they do not partake of the same phenomena. From now on, I will consider the two terms "clipping" and "truncation" as synonyms, and "shortening" as a hyperonym comprising not only clipping/truncation as one of its possible linguistic realizations, but also blends, acronyms, etc., word-formation devices which will not be studied in this paper.

Let me now examine the definitions given by linguists for "clipping" or "truncation". Clipping is generally considered a linguistic phenomenon consisting in cutting up, trimming, or "mincing" a word, so as to produce a shorter version of this word by loss of material. The first two definitions are borrowed from Bauer and adopt a semantic and stylistic approach, clipping being negatively defined as a process without any semantic consequences, but with a change in the stylistic value:

Clipping refers to the process whereby a lexeme (simplex or complex) is shortened, while retaining the same meaning and still being a member of the same form class. Frequently clipping results in a change of stylistic level. [Bauer 1993: 233]

Another type of shortening is clipping. Clipping is the process of shortening a word without changing its meaning or part of speech. As will be clear from the examples given below, clipping frequently does change the stylistic value of the word. [Bauer 1994: 40]

\footnotetext{
${ }^{3}$ Clipping will not be defined as in Deschamps et al. [2004: 30]: "Clipping is the name given to the reduction in length of tense vowels or diphthongs when they are followed by a voiceless obstruent".
} 
Katamba provides a somewhat related definition, but adds a phonological dimension to his definition:

Clipping is the term for the formation of a new word-form, with the same meaning as the original lexical term, by lopping off a portion and reducing it to a monosyllabic or disyllabic rump. [Katamba 2005: 180]

As for Stockwell \& Minkova [2003: 10], they add a syntactic element by noting that clipping is not restricted to a single existing word, but can also apply to a whole phrase: $m o b(<<$ mobile vulgus); zoo (<< zoological garden).

The grammatical or syntactic dimension is also tackled by Tournier [1985: 299] who notes that clipped forms are essentially nouns, but also adjectives, verbs, but more rarely adverbs and prepositions, and even more rarely interjections and conjunctions ('cos). A short statistical survey I have carried out on a list of 290 clippings provided by Wikipedia ${ }^{4}$ confirms Tournier's analysis and gives the following results:

- nominal clipped forms: 265 (91.38\%)

- adjectival clipped forms: $20(6.90 \%)$

- verbal clipped forms: 3 (1.03\%)

- adverbial clipped forms: $2(0.69 \%)$

What is interesting to note is that adjectival clipped forms are often converted into nouns, which confirms the supremacy of nouns as clipped forms (bisexual $>>$ bi; traditional $>>$ trad, etc.). This nominal nature can be the first noticeable tendency in the study of clipping.

If clipping is inevitably linked to morphology, as it consists in cutting up, mincing, trimming or deleting a portion of its constituent part, the word "morphology" is nevertheless rarely mentioned. Yet, it seems that clipping is originally defined according to morphological criteria. What are the recurrent morphological patterns found in English?

Three main patterns can be found, with another border-line pattern which can be added:

- Clipping of the final part, of the end of the word, back-clipping (apocopation or apocope): bi $(<<$ bisexual); binos $(<<$ binoculars); mike $(<<$ microphone). It is by far the most frequent case, accounting for 3 cases out of 4 (Tournier). Even discontinuous pieces can be clipped, as with sci-fi $(<<$ science fiction); sitcom $(<<$ situation comedy); biopic ( $<<$ biographical picture); modem ( $<<$ modulator demodulator), etc. Clipping is also very often linked to backformation: some authors such as Stockwell \& Minkova [2003] or Bauer [1993: 176] consider backformations as cases of shortening: edit $(<<$ editor); burgle $(<<$ burglar); peddlar $(<<$ peddle). There are pros and cons to considering backformations as examples of clippings; I personally consider backformations to be different from clippings, because backformations are always opaque, no longer transparent, whereas the origins of most clipped forms can still be traced back; and backformations change the word-class, whereas it is not the case for clipping.

\footnotetext{
${ }^{4}$ http://en.wikipedia.org/wiki/List_of_English_apocopations
} 
- Clipping of the initial part, of the beginning of the word, fore-clipping (apheresis): fro $(<<$ Afro); loid $(<<$ celluloid); Yard $(<<$ montagnard), accounting for 1 case out of 5 .

- Clipping of both the initial and the final parts of the word (syncope): jam $(<<$ pajamas); shrink (<< head-shrinker); van ( $<<$ advantage); flu ( $<<$ influenza); fridge $(<<$ refrigerator $)$.

- Another related though different pattern can be added: it could be called median clipping ( $6 \%$ according to Tournier [1985]), in which the middle of the word is dropped: paratrooper $(<<$ parachute trooper); breathalyser $(<<$ breath analyser); smog $(<<$ smoke fog). I think it is better to treat this phenomenon as a "contraction" rather than as a real case of "median clipping", as this last phenomenon could be considered as a case of blending ("mot valise" in French, or "mixonyme" for Pottier [1987: 47]). It is indeed sometimes hard to decide if we are confronted with clipping or blending: edbiz. According to Bauer [1993: 233], if there is compound stress, it is a clipping; if there is simple word stress, it is a blend.

The tendency we can note here is the supremacy of back-clipping over the other three types of clipping. Proof of this is that the list of "apocopations" provided by Wikipedia has no counterpart for "apheresis" or "syncope".

Another characteristic feature of clipping is that once a word has been clipped, it can become completely autonomous and be combined with other word-formation processes. An example borrowed from Bauer [1993: 176] is commitology, "the study of committees". Let me give purely discursive creations, showing the infinite morpho-lexical creativity of English. The following two examples have been borrowed from the American situation comedy - I mean "sitcom" - How I Met Your Mother:

These swords represent our brohood (S.1, Ep.8)

- We're bros [...] we're going to have one last awesome night as bros. It's a broing away party. A special broccasion. A bro-choice rally. A brotime of the Apollo. - No, don't bro me!

Once a clipped form has become lexicalized as such, it can adopt all the properties of the full form, such as tense for the verb, plural marker for the noun, etc. For instance, gym, fridge and phone can be pluralized: gyms, fridges and phones. The noun disrespect has been clipped into diss, but cannot really be pluralized because of its use as an uncountable noun. It has nonetheless given way to the clipped verb diss following a conversion / functional shift process, and it is possible to say: Stop dissing me!

Some clipped forms happen to get so autonomous that they are finally perceived and considered as the unmarked, standard forms (the same phenomenon is observed with euphemism): fridge ( $<<$ refrigerator). Sometimes, the motivation between the full form and the clipped form is sometimes lost - a phenomenon known as "opacification"; the following clipped forms are classified from the most transparent to the most opaque: flu $(<<$ influenza); van ( $<<$ caravan); miss ( $<<$ mistress); fence ( $<<$ defence); gipsy $(<<$ Egyptian); gin $(<<$ Geneva); gym ( $<<$ gymnasium); piano $(<<$ pianoforte); cello $(<<$ violoncello); bus $(<<$ omnibus); pants ( $<<$ pantaloons); pram $(<<$ perambulator $)$, etc. This leads me to consider the semantic function of clipping in English. 


\section{The semantic role of clipping}

We may wonder what the role of clipping is, as the process of shortening words provides two lexemes with basically the same signified, which goes against the economy principle in language:

Clipping always provides synonymous words from the same base but here the different style level (not the different meaning) allows both to co-exist [Bauer 1994: 81]

Plag [2003: 22-23] offers a possible explanation as to the meaning associated with clipping:

Additionally, the question may arise of what meaning is associated with truncations. What exactly is the semantic difference between Ronald and Ron, laboratory and lab? Although maybe not particularly obvious, it seems that the truncations, in addition to the meaning of the base, signal the familiarity of the speaker with the entity s/he is referring to. The meaning of familiarity can be seen as the expression of a type of social meaning through which speakers signal their belonging to a certain group. In sum, truncations can be assigned a meaning, but the nature of the morph expressing that meaning is problematic.

Clippings appear as a rather mixed bag of forms abbreviated from larger words, which however, share a common function, namely to express familiarity with the denotation of the derivative. [...] Thus, lab is used by people who work in laboratories, demo is part of the vocabulary of people who attend demonstrations ${ }^{5}$, and so on. Some clippings find their way into larger communities of speakers, in which case they lose their in-group flavour, as for example ad (for advertisement).

What is/are then the semantic difference/s between clipped forms and full forms (base lexemes)? It seems that three cases can be found:

$1 /$ either the clipped form and the full form have more or less the same meaning, which is the most frequent case;

$2 /$ the clipped form is marked colloquial or slang compared to the base lexeme which is the unmarked form;

3/ the clipped form belongs to another "register", i.e. its use is restricted to a particular field, following the so-called "specialization of meaning" phenomenon; as a consequence, the clipped form is often felt to be more technical than the full form. The meaning of the clipped form is therefore narrowed, and only one of the meanings is kept in the clipped form ${ }^{6}$. Tournier [1985] and Bassac [2004: 171] offer a couple of examples, for which I have copied the definitions from the Collins:

curiosity: inquisitiveness; rare object

curio: just the object

demonstration: political display; a demonstration by expert, teacher, salesperson demo: only the political display

\footnotetext{
${ }^{5}$ Or people who work in the music industry. Cf. demo (tapes) for songs recorded without being mixed.

${ }^{6}$ This phenomenon is also to be found with borrowing, when the loan word very often specializes in one meaning, while the word in the foreign language from which it has been borrowed kept its polysemous senses.
} 
examination: school, academic; medical; scrutiny exam: just the test

The fact that the clipped forms can pluralize confirms the restriction in meaning: examinations $=$ exams (tests) $=>$ result examination (no plural) (interrogatoire) $=>$ process

Bassac [2004: 172] tends to formalize this phenomenon on a semantic level:

Seuls peuvent être abrégés par apocope les noms qui font référence au résultat et non au processus identifié par le verbe dont ils sont dérivés ${ }^{7}$.

Finally, Bassac [2004: 171] also mentions the semantic constraints bearing on clipping: the clipped form needs to be "long" enough to mean something: demonstration $>>$ demo $>>* d e$.

From this short analysis, I do not think that any strict semantic tendency can be inferred for clipping. Indeed, grammar and syntactic study, as well as semantics do not seem to have more to say on clipping. Would a phonological approach - or at least an approach mixing both morphology and phonology (sometimes referred to as "prosodic morphology") - be more relevant? What if clipping was not a word-formation device after all, as some linguists argue?

\section{Is clipping a word-formation device?}

Some linguists consider clipping as a "marginal" word-formation process, as it does not generate lots of new words. Bassac [2004: 170] refers to clipping as "un processus marginal de construction de mots" and writes:

Les procédés suivants se distinguent des précédents par leur productivité extrêmement réduite. Ils participent à la construction des mots mais ne sont pas généralisables comme les précédents.

Tournier [1985: 298] notes that in COD6 (Concise Oxford Dictionary), a dictionary comprising 74,000 words, there are only 464 back-clipped forms, 121 fore-clipped forms, 14 cases of double clipped forms and 36 cases of median clipped forms, which is indeed a limited number of words compared to the whole. For that reason, some linguists reject the classification of clipping as a word-formation process, such as Haspelmath [2002: 25]:

[...] while these are clearly operations that can be used to create new words (like morphological operations), they do not fall under morphology, because the resulting new words do not show systematic meaning-sound resemblances of the sort that speakers would recognize. If we know that $C D$ is an abbreviation of compact disk, we do not know it as a result of unconscious language acquisition, but because we were explicitly told so. Thus, not all processes of word-creation fall under word-formation, and abbreviations and clippings will play no role in this book.

If a clipped form is considered as a mere abbreviation, it is clear that it is not another form of a given lexeme. Yet, we have to admit that in some cases, the full form would be abnormal or impossible in the same position: gym shoes $(<<$ ??gymnasium shoes); porn star $(<<$

\footnotetext{
${ }^{7}$ The same phenomenon is found in French with clipped forms such as manif and exam.
} 
??pornography star), etc. Clipped forms are also entered in dictionaries like other "genuine" lexical items, and they accept the grammatical inflections which are typical of their word class: nouns obtained by clipping can pluralize: gyms, fridges, phones, gators; verbs obtained by clipping can take ordinary verbal inflections; clipped forms can enter into compounds like any other lexical item: gym shoes, porn star, fridge magnet, phone book, which tends to prove that clipped forms are regular, genuine lexical items.

There are however various questions that still need to be addressed to decide whether clipping is a word-formation process. The first one deals with semantics and consists in deciding whether the clipped form is a new lexeme or just a new surface form, an allomorph, a free variation of the full form (base lexeme). This issue is summarized by Plag [2003: 117]:

The problem [...] boils down to the question of what exactly we mean when we say that a word-formation process should add 'new meaning' to a base, thereby creating a new lexeme. Do we consider the expression of attitude a 'new meaning'? Or only a minor modulation in usage?

In part 2 we have seen that clippings brought - if not a new meaning - a "social meaning" [Plag 2003: 128] carrying a different connotation from the base lexeme. Sometimes, the clipped form takes on a new meaning, or undergoes a narrowing or specialization in meaning. Hence, if we adopt a broad definition of "meaning", we will accept clipping as a wordformation process, like Plag [2003: 117] who considers that

[...] we will therefore assume a notion of word-formation wide enough to accommodate name truncations, clippings, and diminutives as products of word-formation.

The second question deals with morphology, and as Bauer [1994: 40] makes clear, the study of clipping is hard to formalize because the formation of new clipped forms is hard to predict; given this unpredictability, the study of clipping is not supposed to be part of morphology, though most linguists see it as a way of forming new words:

As far as is known, there is no way to predict how much of a word will be clipped off in clipping, nor even which end of the word will be clipped off. Neither is it possible to say that any given syllable will definitely be retained in clipping. Some examples from English are given below:

(36) binoc(ular)s deli(catessen)

(de)tec(tive)

(head-)shrink(er)

op(tical) art

sci(ence) fi(ction)

Since the parts that are deleted in clipping are not clearly morphs in any sense, it is not necessarily the case that clipping is a part of morphology, although it is a way of forming new lexemes.

Hence, if we accept clipping as a word-formation process, this nevertheless calls for a new definition of "morpheme":

Recall that we found a set of words that are derived from other words by truncation (e.g. Ron, Liz, lab, demo). Such derivatives pose the question of what exactly the morph is (and where it is) that - together with the base word - forms the derived word in a compositional manner.

$[\ldots]$ 
In order to save the idea of morphemes as 'things', one could also propose a different analysis of truncation, assuming the existence of a truncation morpheme which has no phonetic content but which crucially triggers the deletion of phonetic material in the base. Alternatively, we could conceptualize the formal side of the truncation morpheme as an empty morph which is filled with material from the base word. [Plag 2003: 22]

The main problem is that what is dropped is rarely a morpheme per se, just like in cases of backformations. If we take the following example, hood ( $<<$ hoodlum), -lum is not an actual morpheme:

\title{
$\underline{\text { hoodlum }} \boldsymbol{\varphi}$
}

1871, Amer.Eng. (first in ref. to San Francisco) "young street rowdy, loafer," later (1877) "young criminal, gangster," of unknown origin, though newspapers have printed myriad stories concocted to account for it. A guess perhaps better than average is that it is from Ger. dial. (Bavarian) Huddellump "ragamuffin."

http://etymonline.com

An identical phenomenon can be observed for lab $(<<$ laboratory):

\author{
laboratory $\mathcal{O}$ \\ 1605, "building set apart for scientific experiments," from M.L. laboratorium "a place for \\ labor or work," from L. laboratus, pp. of laborare "to work" (see labor). Shortened form \\ lab first attested 1895. \\ http://etymonline.com
}

The unpredictable nature of clipping seems confirmed by an example provided by Tournier [1985] who notes the existence of what he calls "suffixation fantaisiste" accompanying clipping: champers $(<<$ champagne); beano ( $<<$ bean feast), etc.

But is the fact that what is trimmed is not an actual morpheme and the supposed unpredictability sufficient to reject clipping as a word-formation process? I do not think so, because we should reject backformations and almost all morphological devices as wordformation processes. This seems all the more relevant as Tournier [1985] nonetheless gives some predictable properties of clipping; for instance, he notes that in case of ambiguity for compounds, the clipped form will be generated by fore-clipping:

\begin{tabular}{|l|l|l|}
\cline { 2 - 3 } \multicolumn{1}{c|}{} & $\begin{array}{l}\text { Troncation antérieure } \\
\text { (réalisée) }\end{array}$ & $\begin{array}{l}\text { Troncation postérieure } \\
\text { (non-réalisée) }\end{array}$ \\
\hline & & \\
\hline iceberg & berg & *ice \\
\hline hamburger & burger & *ham \\
\hline violoncello & cello & *violon \\
\hline telephone & phone & *tele \\
\hline
\end{tabular}

This phenomenon seems rather logical as in compounded structures such as $\mathrm{N}_{2} \mathrm{~N}_{1}, \mathrm{~N}_{1}$ is the head-word, i.e. the main word, the word with the main semantic load in the compound, and therefore the word which needs to be kept, as exemplified by the examples provided by Tournier: case $\left(<<\right.$ suitcase) but $*_{\text {suit }}$; mate $\left(<<\right.$ checkmate) but $*^{*}$ check; pike $(<<$ turnpike) but *turn; quake (<< earthquake) but *earth; roach $(<<$ cockroach) but *cock, etc. Other

\footnotetext{
${ }^{8}$ Tournier is wrong when thinking that hamburger is a compound. Folk etymology may see this word as a compound (cf. burger, hamburger, cheeseburger, etc.), but the "real" etymology proves that it is not the case (see definition on www.etymonline.com: 1889, hamburg steak, from the Ger. city of Hamburg).
} 
examples include plane ( $<<$ aeroplane); bus $(<<$ omnibus), etc. Yet, this rule is not always valid, as shown by the following example: the base lexeme chemotherapy is often clipped into chemo. This word is known as a neo-classical compound (composé savant in French) composed of a pseudo-lexeme (chemo, from Greek) and of a head-word (therapy). Yet, it is the head-word therapy that is dropped.

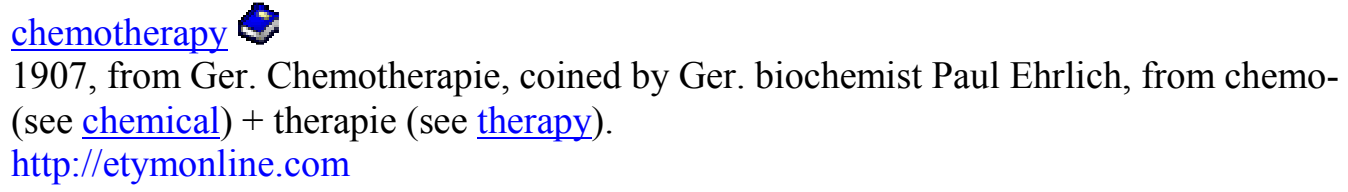

This case is not marginal, and other related examples are provided below (most examples are borrowed from Katamba [2005: 180]):

hyp $<<$ hypochondriac; rep $<<$ reputation; ult $<<$ ultimate; extra $<<$ extraordinary; incog $<<$ incognito; penult $<<$ penultimate; hyper $<<$ hypercritic; bike $<<$ bicycle; mob $<<$ mobile crowd (same phenomenon with "real" compounds, not just neo-classical compounds), etc.

We will not go into detail, but prospective research could include the following questions, as this phenomenon does not seem restricted to neo-classical compounds: do other cases exist? (i.e. is it a recurrent pattern?); do rules governing this type of clipping exist?; what is the role played by semantics?, etc.

If some linguists reject clipping as part of morphology, therefore rejecting its role as a wordformation device, others deem that its study is closely linked to both morphology and phonology; some of them such as Plag [2003: 116] go further and call for the inclusion of the study of clipping in what he calls "prosodic morphology", i.e. the phonology-morphology interaction?

Prosodic morphology deals with the interaction of morphological and prosodic information in determining the structure of complex words.

And indeed, Plag [2003: 116] is one of the (few) linguists to recognize the pivotal role of prosody in the study of clipping:

[W]e will discuss two kinds of word-formation processes in English where prosody plays a prominent role, truncation and blends.

And he even makes it a defining feature of clipping:

Truncation is a process in which the relationship between derived word and its base is expressed by the lack of phonetic material in the derived word. [Plag 2003: 116] ${ }^{10}$

All this means that the definition of clipping has to take a phonological component into account:

Perhaps the most natural way to account for truncation would be to say that it is the process of deleting material itself which is the morph. Under this analysis we would have

\footnotetext{
${ }^{9}$ I will use the term "morphophonological" instead of "prosody" in this paper.

${ }^{10}$ My emphasis.
} 
to considerably extend our definition of morpheme ('smallest meaningful unit') to allow processes of deletion to be counted as 'elements' in the sense of the definition. [Plag 2003: 22]

Consequently, if the study of clipping is difficult to formalize syntactically, morphologically and/or semantically speaking, would phonology offer a way out, and a means of providing an in-depth analysis of this type of shortening?

\section{Consequences and phonological realizations of clipping}

According to Bauer [1993: 233], phonology would not offer the key to the study of clipping, as he deems it impossible to formalize the phonological realizations of clipping; for him, it is impossible to know how many syllables will be kept in the clipped form, whether the final syllable will be open or closed and whether the stressed syllable from the base lexeme will be included or not. Yet, I would like to show that such a claim is not really justified. We have seen that other linguists such as Plag consider clipping to be part and parcel of morphological studies, and this is the option I will adopt in this paper, trying to show how phonology works hand in hand with other devices - semantics, morphology, syntax - to generate new words in English:

Truncations in English are highly systematic, and their systematicity indicates that the knowledge about the structural properties of the categories should be treated as part of the morphological competence of the speakers. [Plag 2003: 117]

The use of the adjective "systematic" and the noun "systematicity" indicates that some rules nonetheless exist and can be used to formalize the study of clipping. Let me now try to bring clipping generating rules into light. Could phonology be more efficient to formalize the study of clipped forms? Plag [2003: 120] deems that the formation of truncated names can indeed be formalized by what he calls "prosodic properties" or "prosodic restrictions":

$[\ldots]$ we have seen that the formation of truncated names is highly systematic and that it is subject to strong prosodic restrictions.

Is it possible to bring out similar "prosodic restrictions" for clippings, even if Plag [2003: 121] considers clipping as "a class of forms that seem to be less coherent than truncated names and $-y$ diminutives"? If clipping is generally described by most linguists as a rather irregular phenomenon, is it not possible nevertheless to find some degree of regularity thanks to phonological restrictions? Following Plag's [2003] analysis, I will consider that the creation of clippings is not that arbitrary but is constrained by phonological restrictions having to do with size and syllable structure (syllabic constituents). Before trying to unearth the phonological restrictions constraining the creation of clippings, I would like to indicate that these restrictions are more tendencies than strict rules.

One of the rules we can point out for clipping is that a long and frequent word is more frequently clipped than a short and rare (scarcely-used) word. As the clipped form is morphologically shorter than the base lexeme, it is very often reduced to a monosyllabic or a disyllabic word, as noted by Stockwell \& Minkova [2003: 10] who write that this "creation by shortening" often results in a monosyllabic word: quiz $(<<$ inquisitive); phone $(<<$ telephone); flu ( $<<$ influenza); plane ( $<<$ airplane), etc. Yet, disyllabic words for clippings can be found. Let me provide the result of a short statistical survey I carried out on the list of 290 clippings provided by Wikipedia: 
- monosyllabic clipped forms: $170(58.62 \%)$

- disyllabic clipped forms: 105 (36.21\%)

- three-syllable clipped forms: $14(4.83 \%)$

- four-syllable clipped forms: $1(0.34 \%)$

Clipped forms rarely exceed two syllables and therefore play a role in language economy, partaking in the so-called "least-effort principle", as they tend to reduce the articulatory and memory efforts necessary to generate the word. $94.83 \%$ of clipped forms are either mono- or disyllabic. The only three- and four-syllable forms found are clippings from compounds: agitprop ( $<<$ agitational propaganda); digi cabes $(<<$ digital cable); hetero $(<<$ heterosexual), etc., which explains the "longer" clipped forms.

We mentioned above that back-clipping is by far the most frequent case (73\%), which leads Tournier [1985: 305] to write:

[L]a troncation ramène le signifiant à la partie nécessaire et suffisante à son identification.

Bassac [2004: 171] also notes the existence of phonological constraints for back-clipping:

Les contraintes qui limitent les possibilités de troncation sont de type phonologique.

Ainsi il est difficile d'abréger la forme d'un mot de façon à laisser subsister une partie seulement d'une syllabe : ainsi *adv est impossible tout autant que *demonstr.

We said fore-clipping was less frequent, and accounted for $19 \%$ of the cases. According to Tournier [1985: 307], it is often used to avoid the "collisions homonymiques qu'entraînerait la troncation postérieure". Hence, there seems to be some phonological motivation generating the creation of clipped forms.

Another tendency is that, according to Tournier [1991a], clipped forms favor one of the four most frequently used morphophonological patterns, and therefore clipped forms tend to respect the 2.3 syllable-length average in English:

La troncation a pour effet de ramener le signifiant d'un mot à l'un des modèles morphophoniques les plus fréquents. [Tournier 1991a: 164]

Tournier [1985: 303] indicates that there are 38 patterns of clipped forms, with a predominance of the first four morphophonological patterns:

CVC (vet): $31.77 \%$

CVCV (demo): $17.48 \%$

CCVC (grad): $9.6 \%$

CVCC (vibes): $8.62 \%$

He adds some details in Tournier [1985], by indicating that the first four morphophonological patterns represent $79 \%$ of the entire cases, $75 \%$ of which end with a consonant sound. He provides the following figures for the words of $1,2,3$ or 4 phonemes, corresponding to $67.47 \%$ : 


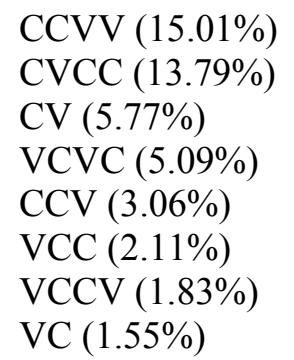

Paillard [2000: 81-82] goes even further than Tournier in the phonological formalization and writes:

La troncation tend à respecter la structure phonologique de la syllabe qui domine dans chaque langue, syllabe fermée en français, syllabe ouverte en anglais :

\begin{tabular}{|c|c|}
\hline CVC en anglais & CVCV en français \\
\hline & \\
\hline lab & labo \\
\hline decaf & déca \\
\hline coke & coca \\
\hline porn & porno \\
\hline
\end{tabular}

But once again, this does not seem to be a golden rule, as exemplified by the following examples: deli $(<<$ delicatessen); condo $(<<$ condominium); demo $(<<$ demonstration); disco $\left(<<\right.$ discotheque), etc. ${ }^{11}$. Again, I carried out a statistical survey on the list of 290 clippings provided by Wikipedia, with the following results:

- clipped forms ending with a consonant sound: 206 (71.03\%)

- clipped forms ending with a vowel sound: 84 (28.97\%)

Although most clipped forms tend to end with a consonant sound, we have to acknowledge that almost $30 \%$ of them nevertheless end with a vowel sound, which is not a negligible figure. If we take a closer look at clipped forms ending with a vowel sound, some tendencies can be observed:

- clipped forms ending in $<_{0}>$ (original $<_{0}>$ ): $55(65.48 \%)$

- clipped forms ending in $<\mathrm{i}>$ (original $<0>$ ): $13(15.48 \%)$

- clipped forms ending in $<_{0}>\left(\right.$ added $\left.<_{0}>\right): 2(2.38 \%)$

- clipped forms ending in $<\mathrm{ie} / \mathrm{y} / \mathrm{i} / \mathrm{ey}>($ added $<\mathrm{ie} / \mathrm{y} / \mathrm{i} / \mathrm{ey}>)$ ): $12(14.28 \%)$

- clipped forms ending in $<\mathrm{a}>($ original $<\mathrm{a}>)$ : $2(2.38 \%)$

It is striking to note that two thirds of vowel sound ending clipped forms end in $<_{0}>$, and that $15 \%$ end in $\left\langle i>\right.$; but more striking is the fact that some clipped forms ending in $<_{0}>$ or $<\mathrm{ie} / \mathrm{y} / \mathrm{i} / \mathrm{ey}>(/ \mathrm{i} /)$ did not originally, because the letter $<_{0}>$ or $<\mathrm{ie} / \mathrm{y} / \mathrm{i} / \mathrm{ey}>$ has been added. There seems to be a template, or rather what I will call a "templatic reduplication". And the template goes further, as all vowel-ending clipped forms end either with a long vowel (or neutralized form for $/ \mathrm{i} /$ ), or with a diphthong (considered as a long vowel), which is coherent with the formation of primary lexemes which cannot end in a short vowel : 55 clipped forms $(65.48 \%)$

\footnotetext{
${ }^{11}$ According to Tournier [1985], clipped forms can also be borrowed directly from the language where the full form originated, such as discothèque, borrowed from French in 1954 (www.etymonline.com) and disco, which explains the open vowel, which is characteristic of the French language.
} 
end in /əu/; 26 clipped forms (30.95\%) end in /i/; 1 clipped form $(1.19 \%)$ ends in /a:/; 1 clipped form (1.19\%) ends in /ar/ and 1 clipped form (1.19\%) ends in /u:/.

For the clipped forms ending in $<_{0}>$, we observe - with the exception of zoo $(<<$ zoological garden), pronounced /u:/ - that all endings are pronounced /əv/, regardless of their origins. A quick survey shows that out of the 55 clipped forms, 31 are neo-classical compounds made up of Greek-origin quasi lexemes: auto $(<<$ auto + mobile $)$; bio $(<<$ bio $+\operatorname{logy})$; hetero $(<<$ hetero + sexual); homo $(<<$ homo + sexual); hypo $(<<$ hypo + dermic $)$; chemo $(<<$ chemo + therapy); intro $(<<$ intro + duction), etc. The tendency is therefore to clip the base lexeme originally a Greek word forming a neo-classical compound - and to keep the first part of the compound ending in $<_{0}>$. But what is even more interesting is that for the other clipped forms ending in $<_{0}>$ (also pronounced / $/ \partial v /$ ), the same tendency exists: 24 clipped forms end in $<_{0}>$ and contained an $<_{0}>$ in the base lexeme, but it is not pronounced /əv/. Hence, there seems to be a phonetic template, a templatic reduplication accounting for the pronunciation of $<_{0}>$ as /ov/ in those words. Let me give a couple of examples ${ }^{12}$ :

limousine /'lıməzi:n/ or /,limə'zi:n/ >> limo /'lımər/

information /, infə'meIfən/ >> info /'infəə⿱一土 /

curiosity /, kjøəri'nsəti/ >> curio /'kjøəriə๘/

brother /'brıðər/ >> bro /brəซ/

camouflage /'kæməfla:3/>> camo /'kæməv/

condominium /, kpndə'mini_əm/ >> condo ${ }^{13} /$ 'kpndəひ/

And this tendency also explains the emergence of this $<-0>$ "suffix" where it was not expected:

combination /, kpmbi'neifən/ >> combi or combo /'kpmbər/

aggravation /, ægrə'veIfən/ >> aggro /'ægrə๘/

lesbian /'lezbi_ən/ >> lesbo /'lezbər / (certainly also by analogy with homo, hetero)

For lack of space, I will not analyze clippings ending in a consonant sound, but I would rather focus on the phonological consequences of clipping, as they seem recurrent, and therefore call for the tendency for clipped forms to become autonomous. Here are some noticeable tendencies:

- stress shift (i.e. a change in stress pattern accompanied by a leftward displacement of the primary stress) such as delica'tessen (20010) >> 'deli (10).

As clipping consists in deleting a part of a word, changes in stress patterns such as stress shifts are bound to occur; the first stress change is the loss of secondary stress when there is one in the full form: application /,æplı'keIfən/ >> app /'æp/; bookmaker /'brk, meıkə/ >>

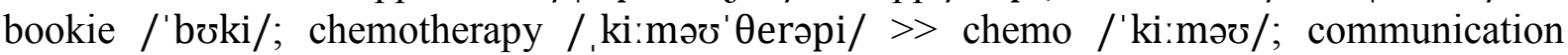
/kə,mju:nı'keIfən/ >> com /'kpm/ or /'ka:m/, etc.

\footnotetext{
${ }^{12}$ All phonetic transcriptions are taken from Well's Longman Pronunciation Dictionary (2008).

${ }^{13}$ This example is quite interesting because it shows that the formation of clippings has also to do with other existing words in the linguistic system; condom would follow the phonological rule put forward by Paillard, but already means something else...
} 
In numerous cases, the change in stress pattern corresponds to what Deschamps et al. [2004: 81] call "the leftward displacement of stress", or "stress shift"14 ("remontée accentuelle" in French). This phonetic change is distributed as follows according to Tournier [1985: 300]:

- in $63 \%$ of cases, the placement of the primary stress remains unchanged.

- in $20 \%$ of cases, the secondary stress becomes the primary stress ${ }^{15}$.

- in $17 \%$ of cases, the primary stress falls on a syllable which was originally unstressed in the full form.

- phonemic change (what Bassac [2004: 171] calls "reconfiguration phonologique"), which can take on three forms:

- vowel change

ammunition /,æmju'nifən/ >> ammo /'æməひ/

aggravation /,ægrə'veIfən/ >> agro /'ægrəひ/

brassiere / 'bræz i_ə/ or /brə'zıər/ >> bra /bra:/

- consonant change

mercenary /'m3:sənər_i/ >> merc /m3:k/

proctor /'proktə/ or /'pra:ktər/ >> prog /prog/ or /pra:g/

bicycle /' baisıkəl/ >> bike /bark/

- consonant and vowel changes

husband /'hızbənd/ >> hubby /'hıbi/

\section{- change in spelling}

As Bauer [1994: 47] writes, clipping can also lead to changes in spelling, without any change in the pronunciation:

Clippings (see above section 3.5) may also, at least in some cases, be orthographically based.

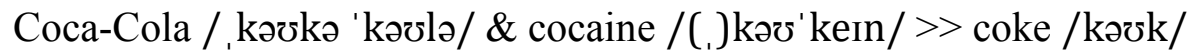

tranquilizer /'trænkwəlaızər/ > trank /trænk/ (*tranq: preferred ending in $<-n k>$. No English word ends in $<-n q>$ )

navigator /'nævigeitə/ >> navvy /'nævi/ (*navy: would be pronounced like navy /'neivi/) civilian /sə'vili_ən/ > civvy /'sıvi/ (*civy would be pronounced /sarvi/)

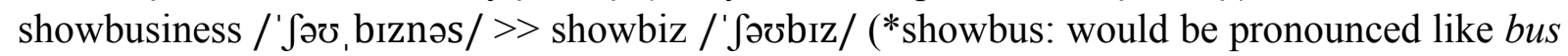
/ b $\Lambda \mathrm{s} /$ )

details /'di:teiəlz/ >> deets /di:tz/

aficionado /ə, $\mathrm{fI} \int \mathrm{i} \_$'na:dəซ/ $/>>$afish $/ \partial, \mathrm{fI} \int /$

delicious /di'lifəs/ $>>$ delish / delif/

microphone /' markrəfəən/ >> mike /mark/

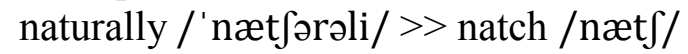

sergeant / sa:dzənt/ $>>$ sarge /sa:dz/

\footnotetext{
${ }^{14}$ The authors refer to stress shift as a means of avoiding stress clash: 'seventeen 'pounds au lieu de *seven'teen 'pounds, where two primary stresses would follow each other.

${ }^{15}$ This is what is called "iambic reversal".
} 
because /bi'kpz/ >> 'cos /kpz/ (*cause: would be confused with the noun or the verb) cousin /'kızən/ >> cuz /'kız/ (*cous: would be pronounced /'ku:s/ or /'kws/; the word cousin is pronounced /' $\mathrm{k} \wedge \mathrm{zIn} /$, and one of the most common realizations of $<\mathrm{u}>$ is $/ \Lambda /$ in English).

All those examples confirm the phonological restrictions on clipping.

\section{- addition of a "suffix"}

As mentioned above, in a significant number of cases, clipping is accompanied by suffixation (or pseudo-suffixation), generally with the addition of the $<-\mathrm{ie}>$ suffix: if vegetables can be clipped into veg, it can also be clipped into veggies, etc. This phenomenon studied by Tournier [1985] is called "suffixation 'affective' (hypocoristique ou euphémique): folkie $<<$ folk singer; undies $<<$ underclothes". Plag [2003: 13] also mentions it:

Sometimes truncation and affixation can occur together, as with formations expressing intimacy or smallness, so called diminutives:

(12) Mandy $<<$ Amanda

Andy $<<$ Andrew

Charlie $<<$ Charles

Patty $<<$ Patricia

Robbie $<<$ Roberta

This phenomenon is known as the so-called "suffixation by $-\mathrm{Y}$ (orthographic variants of which are -IE and sometimes -EE)" [Plag 2003: 117], and Katamba [2005: 181] tends to restrict it to colloquial speech:

In colloquial speech, clippings tend to end in a familiar suffix pronounced /I/ (and spelled

- ies or $-y$ ):

Gerry $>$ Gerald

Monty $>$ Montgomery

Lizzie $>$ Elizabeth

Loony $>$ lunatic

telly $>$ television

poly $>$ polytechnic

Katamba [2005: 181] also points out that this phenomenon is frequently used in Australian English:

Australian English uses clipping and diminutives more frequently and in more varied ways than any other variety of the language.

Aussie $/ \mathrm{pzI} /=$ Australian

Barbie $=$ barbecue $^{16}$

On a semantic and pragmatic level, Katamba [2005: 182] notes that

The semantics and pragmatics of clipping and diminutives is complex. These processes are typically used to express one or more of these notions:

a- small size

b- close emotion - positive

c- close emotion - negative

\footnotetext{
${ }^{16}$ A detailed list can be found in Katamba [2005: 181-182].
} 
d- familiarity (with the entity referred to, and/or with the addressee).

Plag [2003: 117] makes a distinction between diminutives and truncated names + clippings, because for him truncated names and clippings are used to express familiarity, whereas diminutives are used to express familiarity as well as a (usually) positive attitude towards the person or thing referred to ${ }^{17}$.

The question of clipping and diminutives is indeed complex, and I will not go into further detail in their study, as it will lead us too far in this paper.

\section{Conclusion}

In conclusion, if the creation of new clippings is often said to be unpredictable, their inductive formalization is not completely impossible. More than strict golden rules, the rules governing clipping - be they morphological, semantic or phonological - are tendencies. The grammatical restrictions state that the vast majority of clippings are nouns $(91 \%)$, followed by adjectives (6\%), other parts of speech rarely undergoing clipping. The morphological restrictions state that back-clipping is by far the most frequent type, accounting for three quarters of cases, and that the longer the base lexeme is, the more prone it is to be clipped. The semantic restrictions state that the clipped form needs to remain long enough to signify. The morphophonological (prosodic) restrictions first apply to the size of the clipped form; rarely is a clipped form of more than two syllables found, the vast majority of clippings being restricted to monosyllabic clipped forms (58.62\%) and disyllabic clipped forms $(36.21 \%)$. Clipping tends to favor one of the four most frequent morphophonological patterns of primary lexemes.

I also tried to demonstrate that if the structure and formation of clippings are constrained more or less by semantic and syntactic restrictions, phonological restrictions appear more relevant to account for the formalization of clippings. More than semantics or syntax, phonological constituents "play an important role in constraining the type of material to be deleted" in clippings [Plag 2003: 125]. This finding seems to call for a phonological lexicology, or a lexical phonology...

\section{BIBLIOGRAPHY}

BASSAC Christian, Principes de morphologie anglaise, "Linguistica", Pessac, Presses Universitaires de Bordeaux, 2004.

BAUER Laurie, English Word-Formation (1983), Cambridge, "Cambridge textbooks in linguistics", Cambridge University Press, 1993.

---, Introducing Linguistic Morphology (1988), Edinburgh University Press, 1994.

Deschamps Alain, DuChet Jean-Louis, Fournier Jean-Marie, O'NeIL Michael, English Phonology and Graphophonemics, Gap, Ophrys, 2004.

\footnotetext{
${ }^{17}$ Additional references include:

SCHNEIDER Klaus Peter, Diminutives in English, Tübingen, Niemeyer, 2003.

DRESSLER Wolfgang U., "Extragrammatical vs. marginal morphology", in Extragrammatical \& Marginal Morphology, Munich, Lincom, 2000.

DRESSLER Wolfgang \& LAVINIA MERLINI Barbaresi, Morphopragmatics. Diminutives \& Intensifiers in Italian, German \& Other Languages, Berlin, Mouton de Gruyter, 1994.
} 
HaSPElmath Martin, Understanding Morphology, "Understanding Language Series", London, Hodder Education, 2002.

KATAMBA Francis, English Words. Structure, History, Usage (1994), $2^{\text {nd }}$ edition, London and New York, Routledge, 2005.

PAILlaRd Michel, Lexicologie contrastive anglais - français - Formation des mots et construction du sens, Gap - Paris, Ophrys, 2000.

Plag Ingo, Word-Formation in English, "Cambridge Textbooks in linguistics", Cambridge, CUP, 2003.

StockWELl Robert \& Minkova Donka, English Words: History and Structure (2001), Cambridge, CUP, 2003.

TOURNIER Jean, Introduction descriptive à la lexicogénétique de l'anglais contemporain, Paris-Genève, Champion-Slatkine, 1985.

---, Précis de lexicologie anglaise, Nathan Université, 1991a.

---, Structures lexicales de l'anglais : guide alphabétique, Nathan Université, 1991b.

Wells John, Longman Pronunciation Dictionary (1999), $3^{\text {rd }}$ edition, Pearson Longman, 2008.

\section{Webography}

http://en.wikipedia.org/wiki/List_of_English_apocopations

http://www.informatics.sussex.ac.uk/department/docs/punctuation/node20.html

http://etymonline.com 